\title{
Motivação e Satisfação no Trabalho da Polícia Militar: Um estudo de caso no Sertão Pernambucano
}

\author{
Fernanda Roda de Souza Araújo Cassundé ${ }^{1}$; Ana Carolina Brandão Moraes ${ }^{2}$; Arianne Bezerra de Vasconcelos ${ }^{2}$; Celso Alves
} Júnior ${ }^{2}$; Emanuela carvalho de Souza ${ }^{2}$; Robério Dias Pereira ${ }^{2}$; Rosivânia Rodrigues de Alencar ${ }^{2}$

Resumo: Objetivou-se descrever os fatores que contribuem para a satisfação e insatisfação de policiais militares do Sertão Pernambucano. Caracteriza-se por ser uma pesquisa quantitativa, em que a coleta dos dados se deu por meio de questionários e a análise ocorreu por agrupamento das respostas em categorias comuns. Os resultados apontam que para 50,3\% dos profissionais, há um relacionamento agradável com os colegas de trabalho. Já os indicadores relacionados à insatisfação apontam principalmente para os critérios relacionados à ascensão hierárquica, uma vez que apenas $1,3 \%$ concordam serem os métodos justos. A base teórica do estudo está fundamentada em Herzberg, uma vez que os resultados obtidos vão de encontro ao modelo Higiene-Motivação proposto pelo autor.

Palavras-chave: Satisfação, insatisfação; motivação; policiais militares do sertão pernambucano; Herzberg.

\section{Motivation And Job Satisfaction Of The Military Police: A Case Study In The Backwoods Of Pernambucano}

\begin{abstract}
The objective was to describe the factors that contribute to satisfaction and dissatisfaction of the military police of the Wild of Pernambuco. It is characterized for being a quantitative research in which data collection was done through questionnaires and analysis occurred by grouping the responses into common categories. The results show that for $50.3 \%$ of the professionals, there is a nice relationship with co-workers. Have the dissatisfaction related indicators point mainly to the criteria related to the hierarchical rise, since only $1.3 \%$ agree are fair methods. The theoretical basis of this study is based on Herzberg, since the results will Hygiene against motivation model proposed by the author.
\end{abstract}

Keywords: Satisfaction, dissatisfaction; motivation; Military Police of Pernambuco hinterland; Herzberg.

\section{Introdução}

A segurança constitui uma das obrigações do Estado para com os cidadãos, conforme preceitua o Artigo $6^{\circ}$ da nossa Constituição. A Polícia Militar de Pernambuco, como um dos órgãos operativos do sistema de segurança pública estadual, prima no seu dia a dia pela busca do cumprimento de tal mister, buscando se adequar às mudanças que ocorrem nos hábitos da sociedade. Tais mudanças têm origens diversas, como cultura, educação, leis abrandadas, sensação de impunibilidade, entre outros fatores.

Por se tratar de um serviço que lida diretamente com o público, estes profissionais são submetidos à exposição contínua, tendo seus erros propagados de uma maneira muito maior que seus acertos.

\footnotetext{
Docente do Colegiado de Administração - CADM Universidade Federal do Vale do São Francisco - UNIVASF Lattes: http://lattes.cnpq.br/2696430100313826. E-mail: Fernanda.roda@ univasf.edu.br;

2 Acadêmico de Administração da UNIVASF.
} 
Em qualquer meio de comunicação, o tema segurança é abordado frequentemente, onde muitas vezes há o envolvimento de policiais militares, tanto por sua presença, como pela ausência.

Desta forma, Governo do Estado de Pernambuco criou e implantou o Programa Pacto Pela Vida, o qual tem como objetivo principal a redução dos índices de criminalidade no estado, de acordo com as metas traçadas. Como um dos instrumentos para o cumprimento de tais objetivos, encontramos o policial militar, que atua na linha de frente e lida diariamente com diversas situações. Dentro dessa realidade, buscou-se nesta pesquisa, realizada junto ao público interno que trabalha no sertão pernambucano, verificar a Qualidade de Vida no Trabalho, a qual pode exercer forte influência sobre a Motivação e a Satisfação do policial militar e, consequentemente, na qualidade do serviço prestado à população.

\section{Referencial Teórico}

\section{Satisfação com o Trabalho}

Estudos nos campos organizacionais têm discutido diferentes correntes teóricas desde os movimentos das relações humanas, em meados do século XX. Desde então, buscou-se compreender as variáveis que surgem a partir das necessidades humanas e a sua influência na produtividade, Motta (apud Brandão et al, 2014). Nesse contexto, surgiram fatores relevantes relacionados ao comportamento humano no trabalho que se configurou após a revolução industrial, caracterizada pela compra e venda da força de trabalho, onde compreensão de fatores oriundos dessa relação tem despertado interesse de estudiosos sobre comportamento organizacional e contribuído com mudanças significativas para as organizações e o futuro destas.

Segundo Siqueira (apud Agapito, 2014) diversos pesquisadores, através de estudos e pesquisas, identificaram a satisfação como um fator crítico desta relação, podendo se dar de forma negativa ou positiva. Gestores empresariais, preocupados como um bom clima organizacional, também têm buscado entender melhor o envolvimento desse sentimento com o trabalho.

Robbins (2005, p. 66) define a satisfação com o trabalho como "a atitude geral de uma pessoa em relação ao trabalho que realiza". Dessa forma, a satisfação no trabalho é obtida pela geração de sentimentos que os empregados têm em relação às tarefas que desempenham, e isso pode interferir na produtividade.

Morin (apud Andrade, 2007) em pesquisa realizada buscando entender os sentidos do trabalho, o descreveu como um ambiente de relacionamento com outros indivíduos, onde se procura alguma coisa pra fazer, para fugir do tédio e alcançar um objetivo na vida. Portanto, o trabalho agregaria valor 
à vida, traria motivação e influenciaria na produtividade dos indivíduos. No entanto, o trabalho só tem sentido para uma pessoa enquanto ela achar importante e útil para ela.

Para compreender melhor o comportamento dos indivíduos nas organizações é necessário levar em consideração fatores típicos da natureza do trabalho, como: chefia, salário, colegas de trabalho, oportunidades de promoção e o próprio cargo ocupado.

Sendo assim, o funcionário faz uma avaliação da sua satisfação ou insatisfação, resultante de um somatório desses elementos, além de aspectos ligados às políticas estabelecidas pelas organizações, como: obediência a regras, vínculos afetivos, padrões de desempenho e condições de trabalho muito abaixo do esperado; podendo, assim, apresentar-se de diferentes formas. ROBBINS (apud Andrade, 2007).

Em relação à insatisfação dos funcionários com o trabalho, nota-se que, na maioria das vezes, resulta em consequências ruins para o funcionário e, sobretudo, para a organização. Conforme Robbins (2005), essa insatisfação pode ser causada por vários fatores. Uma delas é a busca de um novo emprego, acarretando no abandono da empresa por parte do funcionário; outra pode ser a negligência, que abrange entre outras questões a do absenteísmo (ausência do funcionário), a redução do empenho, entre outros fatores.

Esse mesmo autor aborda ainda que esses funcionários podem melhorar as condições por meio de conversas e sugestões de melhorias junto a seus superiores e outras formas de comunicação. A lealdade também pode ser outra forma, assim, o funcionário espera passivamente que as condições melhorem, confiante que seus dirigentes irão perceber o que deverá ser feito.

Deste modo, é necessário investimento na valorização dos funcionários com aspectos motivadores, com o objetivo de elevar a autoestima e bem estar de cada um deles, aumentando, assim, o nível de satisfação e, consequentemente, trazendo colaboradores mais comprometidos com menor índice de rotatividade e máxima eficiência para as organizações. Portanto, vê-se o quanto é importante para qualquer empresa motivar seus funcionários para que façam suas atividades com prazer e satisfação.

\section{Qualidade De Vida No Trabalho (QVT)}

A Qualidade de Vida no Trabalho não é fator recente de preocupação para o homem, que constantemente buscou maneiras de facilitar e trazer satisfação e bem-estar ao trabalhador na execução de suas tarefas. Essa preocupação, segundo França Jr. E Pilatti (2004), acentua-se com o advento da Revolução Industrial, que passou a expor os trabalhadores a precárias condições de trabalho e um sistema de linha de produção que fazia do trabalho algo repetitivo e desmotivante. Em meados do século XX, surgiram vários estudos que hoje são fontes essenciais para à atual teoria de Qualidade de 
Vida no Trabalho. Dentre os estudiosos da época, cita-se Elton Mayo, Abrahan Maslow, Douglas McGregor e Frederick Herzberg (RODRIGUES, 1999, apud VASCONCELOS, 2001).

A década de 1970 foi um marco no desenvolvimento da QVT, que tinha como base a saúde, segurança e satisfação dos trabalhadores, e seguiu inicialmente a escola sócio-técnica, onde a "organização do trabalho foi colocada como princípio maior, a partir da análise e reestruturação das tarefas" (FRANÇA JR.; PILATTI, 2004, p.5). Segundo Limongi-França (1997, apud VASCONCELOS, 2001, p.25), a QVT é como o "conjunto das ações de uma empresa que envolve a implantação de melhorias e inovações gerenciais e tecnológicas no ambiente de trabalho". Ou seja, envolve, entre outras características, a participação do empregado nas decisões organizacionais; reestruturação de tarefas, estruturas e sistemas para que ofereçam maior liberdade e satisfação no trabalho; sistemas de compensações que valorizam o trabalho; adequação do ambiente de trabalho às necessidades individuais do trabalhador e satisfação com o trabalho.

Nesse contexto, a QVT está englobada em um tema multidisciplinar, recebendo contribuições e possuindo diferentes abordagens nos diversos campos do conhecimento a que está ligada. De fato, por se tratar de um tema extremamente amplo, possui um certo grau de subjetividade o que torna difícil a tarefa de formular um conceito capaz de abarcar toda a sua complexidade.

\section{Motivação}

Apresentar estudos sobre motivação é abordar um tema bem debatido e composto por diferentes teorias. Mas essas conjecturas apresentam uma base comum, como traz Bergamini, através das ideias de Murray, no artigo "Objetivos motivacionais e estilos de comportamento": "É claro que diferentes teóricos têm diferentes concepções sobre motivação. Não obstante, há acordo geral em que um motivo é um fator interno que dá início, dirige e integra o comportamento de uma pessoa." (MURRAY, 1971 apud BERGAMINI, 1978 p. 14).

Para seguir o fluxo do processo de motivação deve-se entender que um motivo se divide em dois componentes, o impulso e o objetivo, sendo impulso um processo interno que incita uma pessoa a uma ação, podendo claramente ser influenciado pelo ambiento externo, como a temperatura. Murray explica que o motivo acaba quando o objetivo estabelecido pela pessoa é atingido ou ele obtém a recompensa, dois fatores (objetivo e recompensa) que geram uma certa saciedade sobre o motivo. Dessa maneira, o objetivo ou recompensa podem ser externos, mas o processo de termino do impulso é por si mesmo interno. (MURRAY, 1971, apud BERGAMINI, 1978).

Toda a força do comportamento está sempre dirigida para um alvo. As pessoas buscam saúde, conforto, auto realização e fogem de condições que ameaçam a saúde, esse conforto ou a possibilidade de auto realização (BERGAMINI, 1976, apud BERGAMINI, 1978, p. 17). 
Quando Herzberg apresenta sua teoria ao mundo, ele dá um grande passo referente às teorias de Maslow e McGregor. Herzberg basicamente agrupou todos os fatores detectados por Maslow e McGregor e os subdividiu em dois grandes grupos, os fatores higiênicos e os fatores motivacionais, realizando um processo de entrevista com duzentos engenheiros e contadores para chegar a tal divisão, (BERGAMINI, 1978). Para entender melhor os dois fatores, Herzberg fala o seguinte:

Essa hipótese sugeria que os fatores que influíam na produção de satisfação profissional eram desligados e distintos dos fatores que levavam à satisfação profissional. Uma vez que os fatores desligados tinham que ser considerados dependendo da satisfação ou da insatisfação profissional, esses dois sentimentos não eram contraditórios entre si. O oposto de satisfação profissional não seria a insatisfação, mas sim nenhuma satisfação profissional; e da mesma maneira, o oposto da insatisfação profissional seria nenhuma satisfação profissional e não satisfação. (HERZBERG, 1964 apud BERGAMINI, 1978, p. 21).

Basicamente ele diz que realização, trabalho, desenvolvimento e reconhecimento são fatores motivacionais - porém, a sua ausência não traz desmotivação - e a política da organização, condições de trabalho supervisão, remuneração, segurança e as relações interpessoais são os fatores higiênicos sua ausência desmotiva, mas a sua presença não é condição motivante (HERZBERG, 1964, apud BERGAMINI 1978).

\section{Método}

A metodologia empregada consistiu na aplicação de um questionário como instrumento de pesquisa. Esse método foi escolhido por possibilitar que fossem ouvidas pessoas localizadas em regiões distantes, sem a necessidade da presença dos pesquisadores. O questionário foi aplicado durante o mês de novembro de 2014 nas Organizações Militares Estaduais da Polícia Militar de Pernambuco, localizadas no sertão pernambucano, todas subordinadas à Diretoria Integrada do Sertão II, a saber:

- $3^{\circ}$ Batalhão de Polícia Militar - Arcoverde;

- $5^{\circ}$ Batalhão de Polícia Militar - Petrolina;

- $7^{\circ}$ Batalhão de Polícia Militar - Ouricuri;

- $8^{\circ}$ Batalhão de Polícia Militar - Salgueiro;

- 14º Batalhão de Polícia Militar - Serra Talhada;

- 23ํㅡㄹ Batalhão de Polícia Militar - Afogados da Ingazeira;

- $1^{\text {a }}$ Companhia Independente de Polícia Militar - Belém do São Francisco;

- 2a Companhia Independente de Polícia Militar - Cabrobó; 
- $4^{\mathrm{a}}$ Companhia Independente de Polícia Militar - Petrolândia;

- $7^{\text {a }}$ Companhia Independente de Polícia Militar - Santa Maria da Boa Vista.

Abaixo, na Figura 1, o organograma da Diretoria Integrada do Interior II com as respectivas unidades militares que lhe são subordinadas.

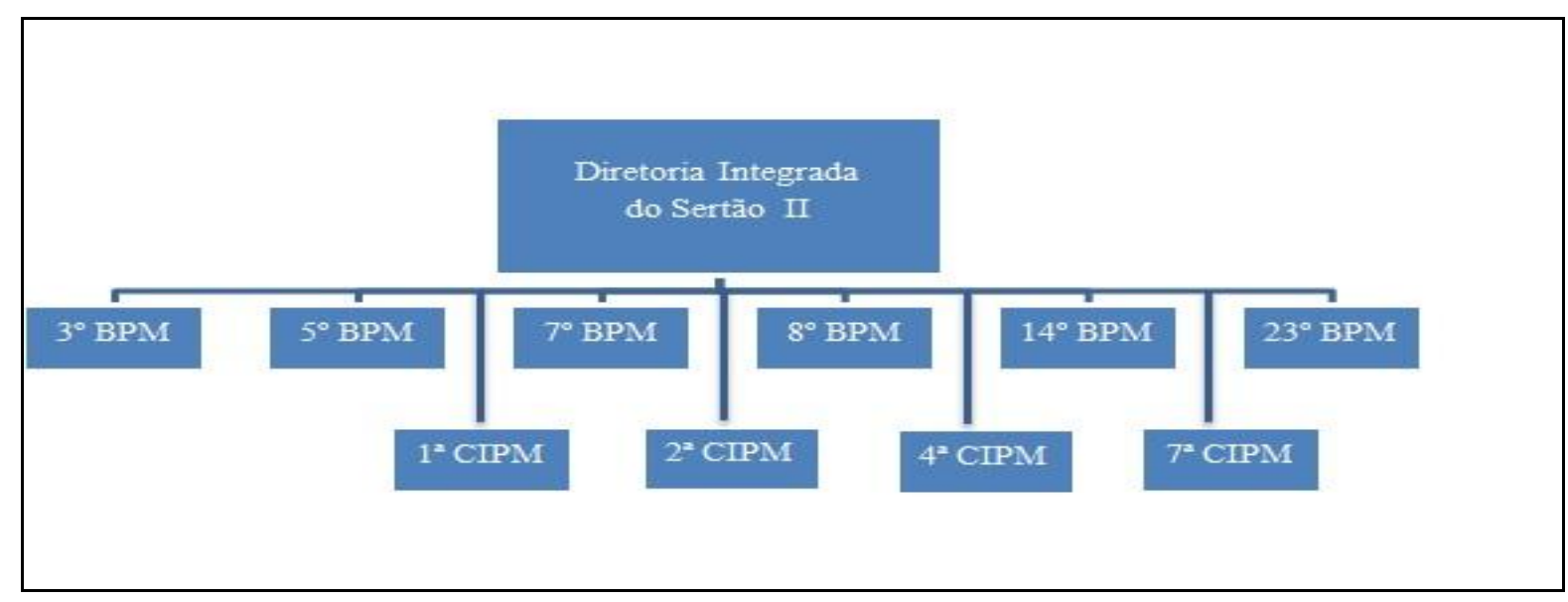

Figura 1- Organograma da DINTER II Fonte: Polícia Militar de Pernambuco

A Polícia Militar de Pernambuco cumpre sua missão conforme o que preceitua o Artigo 144, Inciso V, da Constituição Federal. Com suas unidades policiais localizadas geograficamente distantes da capital do estado, seus componentes possivelmente vivenciam, na rotina diária, situações diferentes dos que trabalham na região metropolitana, tanto no aspecto geográfico como também profissional.

Para a formulação do questionário foram utilizadas perguntas dos tipos Dicotômica, Fechada e Aberta, assim como também escalas tipo Likert, com quatro opções de preenchimento $($ Concordo Totalmente $=1$, Concordo $=2$, Discordo $=3$ e Discordo Totalmente $=4)$, Qualitativa e Quantitativa.

Em um universo de 2972 (dois mil novecentos e setenta e dois) policiais militares lotados no sertão, 154 (cento cinquenta e quatro) pessoas foram selecionadas por amostragem, a partir do quantitativo máximo de policiais por batalhão, conforme a fórmula de Gil (1999), seguindo os Critérios de Confiança 1 e de Erro Máximo Permitido 4, tendo participado pessoas de ambos os sexos, que trabalham tanto no campo administrativo dos quartéis, como no de policiamento ostensivo ordinário e especializado, atingindo diversos níveis hierárquicos e tempo de serviço, buscando, com isso, obter uma visão macro das situações vivenciadas e a consequente mensuração da satisfação e motivação do efetivo. 


\section{Análise dos Resultados}

Tendo em vista os dados obtidos, foi possível compreender os principais motivos de satisfação e insatisfação do quadro PMPE e, consequentemente, inferir sobre os possíveis descontentamentos quanto à escolha profissional. Os dados apontam que apenas 6,5\% concordam totalmente serem ideais as viaturas utilizadas, visto que o policiamento ordinário executa essencialmente suas atividades em rondas pela cidade. Outro ponto fundamental para a satisfação desses profissionais está intimamente ligado à presença de ar condicionado no serviço de patrulhamento; 79,9\% apontam ser item essencial às atividades.

Com essa análise é possível observar que o ambiente físico de trabalho necessita de práticas que maximizem a QVT, tornando mais agradável a execução de atividades simples como, por exemplo, um aperfeiçoamento nas viaturas para patrulha supracitadas. A propósito, os programas de bem-estar são geralmente adotados por organizações que procuram prevenir problemas de saúde dos seus funcionários. A importância do caráter profilático de tais programas parte do reconhecimento do seu efeito sobre o comportamento da equipe e estilo de vida fora do trabalho, encorajando também as pessoas a melhorarem seu padrão de saúde.

No que se refere à saúde do servidor existe o SISMEPE (Sistema de Saúde dos Militares do Estado de Pernambuco), o qual visa prestar o atendimento médico aos militares estaduais, funcionários civis e seus dependentes, descontando compulsoriamente um percentual de $1 \%$ sobre o soldo (salário base), que pode variar dependendo do acréscimo de familiares (esposas e/ou filhos). Atualmente o sistema opera com um déficit, pois o que é arrecadado não é suficiente para cobrir as despesas dos usuários. Baseado nesses fatos foi questionado o se valor pago ao SIMESPE era suficiente para um atendimento médico de boa qualidade, onde $60,4 \%$ discordaram e apenas 12,3\% concordaram plenamente, demonstrando que a maioria tem o entendimento que o valor que é pago é insuficiente para um bom atendimento médico.

Em relação à facilidade no acesso ao atendimento médico da PMPE, os dados mostram que grande parte dos entrevistados, $78,3 \%$, não concorda que há facilidade, e apenas $21,7 \%$ concorda que há, fato que pode estar relacionado à inadimplência do SISMEPE com os convênios médicos, devido ao déficit financeiro do sistema, ocasionando a interrupção do serviço.

No quesito referente à disposição em pagar um valor mais alto para ter um atendimento de melhor qualidade constata-se que a maior parte está disposta a pagar para ter este benefício (GRÁFICO 1), conforme as seguintes respostas: concordo totalmente 32,5\%, concordo 34,5\%, 10,4\% discordo e $22,7 \%$ discordo totalmente. Porém, quanto ao desconto obrigatório, 60,70\% responderam que não acham justa a adesão compulsória (GRÁFICO 2) e, mesmo participando do SISMEPE, $27,90 \%$ deles possuem um plano de saúde particular. 


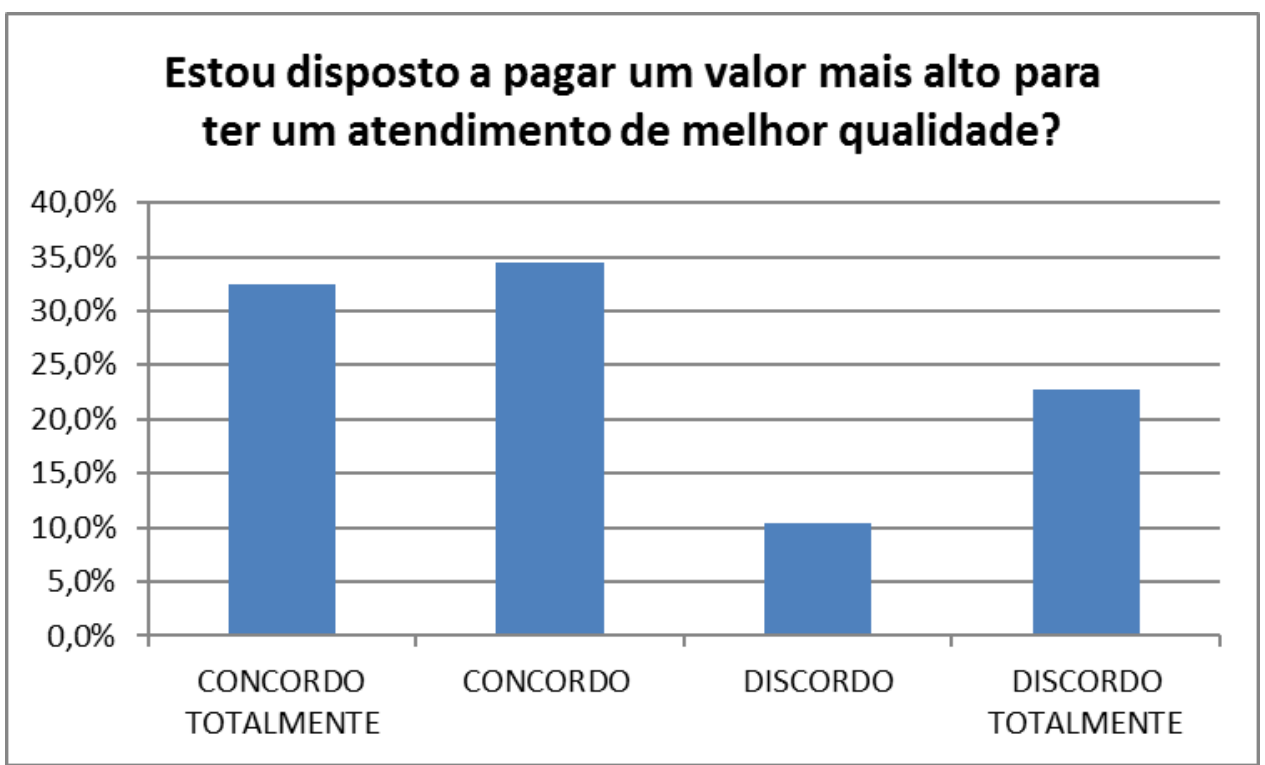

Gráfico 01. Estou disposto a pagar um valor mais alto para ter um atendimento de melhor qualidade?

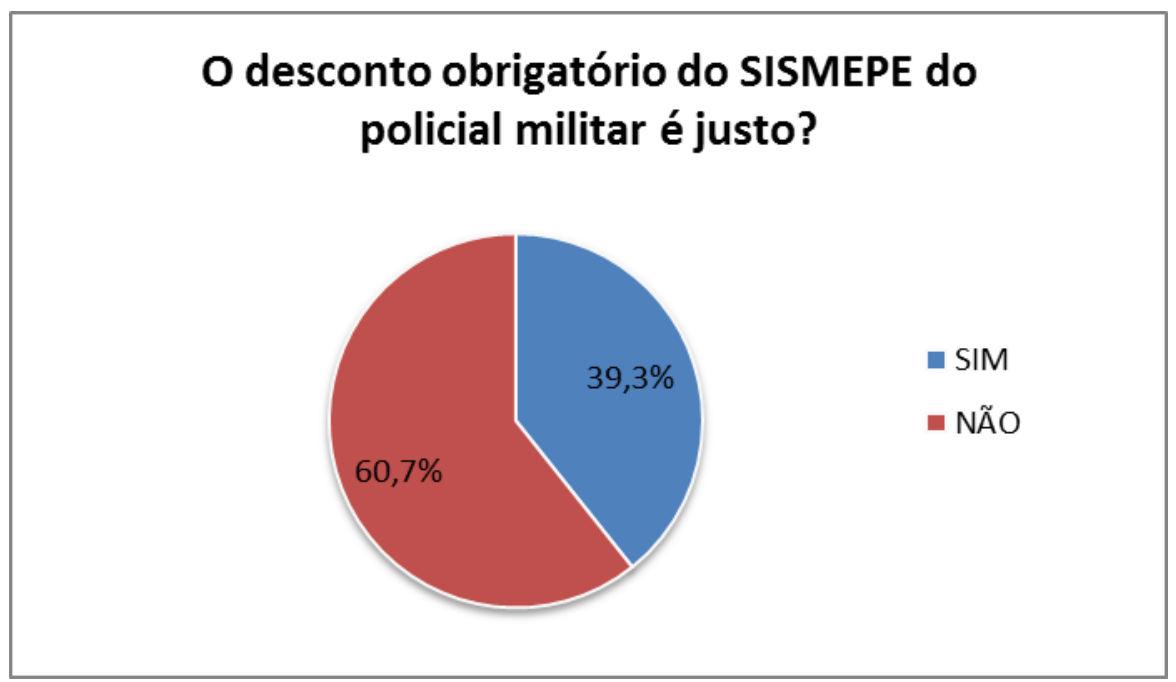

Gráfico 02. O desconto obrigatório do SISMEPE do policial militar é justo?

No que diz respeito à qualidade de vida no trabalho, relacionada à condição das viaturas para o serviço de policiamento, $74,1 \%$ acreditam que elas não sejam ideias, conforme gráfico 3 . 


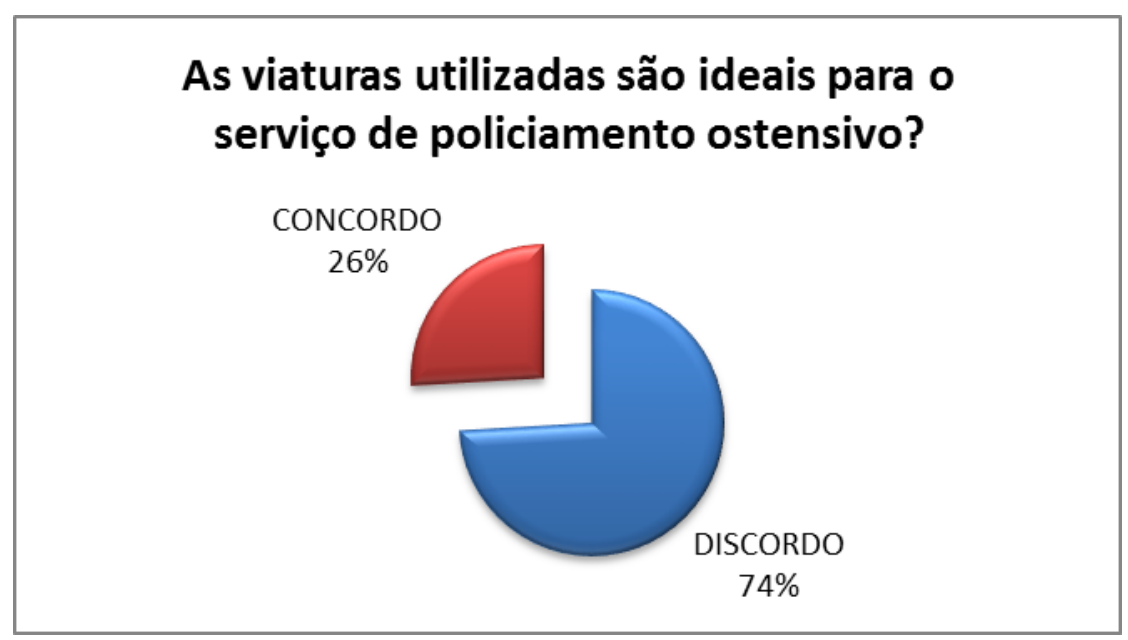

Gráfico 03. As viaturas utilizadas são ideais para o serviço de policiamento ostensivo?

Com relação ao ar condicionado ser um item fundamental para o bem estar no serviço de patrulhamento, 92,2\% dos entrevistados concordaram, evidenciando que a maioria acredita que o item é fundamental, fato importante, pois a maior parte das viaturas do serviço de policiamento ostensivo não possui ar-condicionado, o que pode influenciar diretamente na qualidade do atendimento das ocorrências devido às altas temperaturas da região, gerando fadiga e estresse.

No aspecto relacionado aos critérios adotados para ascensão hierárquica, apenas 1,3\% concordou totalmente que são justos e 10,4\% concordam, sendo que a grande maioria avaliou negativamente, com $35,7 \%$ discordando e $52,6 \%$ discordando totalmente quanto à justiça desses critérios, dados que demonstram que a maioria entende que a forma de ascensão é injusta, o que pode impactar negativamente na satisfação e motivação. Ver gráfico 4 a seguir:




Quanto ao relacionamento agradável com os colegas de trabalho, 96\% acreditam ter um relacionamento agradável, restando apenas $4 \%$ de não concordância com esse fator, mostrando que, de modo geral, há uma boa relação de trabalho entre os membros da organização.

Sobre o código disciplinar dos militares e a justiça, no que se refere aos quesitos "Direitos, Concessões e Punições", foram obtidos os seguintes resultados: $68,5 \%$ da amostra acha que o Código não é justo em relação aos direitos, 67,8\% têm a mesma opinião sobre as concessões e 90,4\% não acham justas as punições. Isto indica um alto grau de descontentamento dos militares entrevistados no que se refere a esses aspectos do código disciplinar, sendo que 34,7\% afirmam nunca o terem lido. Nas questões ligadas à moradia, 29,8\% responderam que moram em casa alugada e $72 \%$ afirmam que morariam em uma vila militar, pagando um valor mensal abaixo do praticado no mercado, caso a PMPE disponibilizasse esse tipo de moradia. Ver tabela 1 a seguir.

Tabela 1 -Visto que sou militar e tenho o conhecimento do teor do Código Disciplinar dos Militares do Estado de Pernambuco, acho justo no que tange a punições.

\begin{tabular}{c|c}
\cline { 2 - 2 } & PERCENTUAL VÁLIDO \\
\hline SIM & $9,46 \%$ \\
\hline NÃO & $90,54 \%$ \\
\hline TOTAL & $100 \%$ \\
\hline
\end{tabular}

Quanto aos motivos do ingresso na carreira policial militar, $18 \%$ indicaram que foi devido à aptidão para o serviço, $48 \%$ por uma questão de oportunidade e $34 \%$ por estabilidade financeira, evidenciando que apenas a minoria está no serviço militar por motivo de vocação e preferência profissional. Sobre a possibilidade de saída da PMPE caso tivesse outra oportunidade de emprego, $50,3 \%$ concordam totalmente que sairiam, 29,1\% concordam, 10,6\% discordam e 9,9\% discordam totalmente, dados que chamam a atenção, pois mostram que a maioria deles sairia da PMPE caso tivessem outra oportunidade.

Sobre os motivos de uma possível saída da corporação, 87,3\% atribuem à melhoria salarial como a maior motivação, demonstrando um altíssimo índice de insatisfação com a atual remuneração, onde 91,6\% têm a visão que o salário não é compatível com a função exercida na segurança pública.

O tempo do curso de treinamento do profissional é um período importante para um bom desempenho de suas funções e, quando questionados sobre a suficiência do tempo de formação para torná-los aptos para o serviço de policial militar, foram obtidos os seguintes resultados: concordo totalmente $20,9 \%$, concordo $41,8 \%$, discordo $29,4 \%$ e discordo totalmente $7,8 \%$.

Dos servidores entrevistados, 42,4\% não frequentam curso superior, 19,9\% frequentam para melhorar a formação, 14,6\% para prestar outro concurso e 23,2\% para as duas anteriores. Já em relação ao grau de satisfação com a profissão, 40,8\% indicam estarem satisfeitos e 59,2\% não estarem satisfeitos e, para motivação, $31,7 \%$ se dizem motivados e 68,2 não motivados, conforme a TABELA 2 e a TABELA 3. 
Tabela 2 - Em relação ao grau de satisfação com a profissão, me sinto

\begin{tabular}{c|c}
\hline OPÇÃO & PERCENTUAL VÁLIDO \\
\hline MUITO SATISFEITO & $4,61 \%$ \\
\hline SATISFEITO & $36,18 \%$ \\
\hline POUCO SATISFEITO & $39,47 \%$ \\
\hline NÃO SATISFEITO & $19,74 \%$ \\
\hline TOTAL & $100 \%$ \\
\hline
\end{tabular}

Tabela 3 - Em relação ao grau de motivação em meu trabalho, me sinto

\begin{tabular}{c|c}
\hline OPÇÃO & PORCENTAGEM \\
\hline MUITO MOTIVADO & $2,65 \%$ \\
\hline MOTIVADO & $29,14 \%$ \\
\hline POUCO MOTIVADO & $49 \%$ \\
\hline NÃO MOTIVADO & $19,21 \%$ \\
\hline TOTAL & $100 \%$ \\
\hline
\end{tabular}

\section{Conclusões}

Os avanços nos campos organizacionais em relação ao comportamento humano têm sido considerados pela gestão de pessoas um marco histórico do relacionamento entre as pessoas e a organização, uma vez que o funcionário passou a ser visto de uma forma mais humanizada, deixando de ser uma extensão da máquina para se tornar um parceiro das organizações.

Dessa forma, a valorização e investimento no profissional torna-se um dos pontos principais para uma boa performance de qualquer organização. Assim, faz-se necessária uma intensificação no departamento de gestão de pessoas, para que funcionários sintam-se motivados e satisfeitos no trabalho e tenham um bom desempenho na função.

A Polícia Militar, como organização pública, têm sofrido inúmeras críticas pelo trabalho prestado à população. Uma pesquisa realizada em abril de 2014 pelo Instituto de Pesquisa Maurício de Nassau (IPMN) revelou que a profissão de policial é a menos admirada pelos recifenses. Apesar da pesquisa ter sido aplicada em apenas uma cidade de Pernambuco, sabe-se, pelas constantes críticas divulgadas pela mídia, que isso não difere da opinião do restante do estado.

Inúmeros fatores podem estar relacionados ao desempenho de funcionários e organização, bem como fatores de motivação, satisfação, preparação para a função a ser exercida, entre muitos outros.

162 Id en lime Revista de Psicologia. Ano 9, №. 26, Supl. Esp. Abril/2015 - ISSN 1981-1179. Edição eletrônica em http://idonline.emnuvens.com.br/id 
O objetivo desse trabalho, portanto, foi analisar o grau de motivação e satisfação com a profissão dos policiais militares do Sertão de Pernambuco. Utilizou-se como fundamentação os estudos de Frederick Herzberg com base na teoria bifatorial, tendo em vista os fatores higiênicos e motivacionais como dados da pesquisa.

Os resultados obtidos na pesquisa em relação ao fator satisfação indicam que 59,2\% dos policiais militares se sentem insatisfeitos com o trabalho, sendo que os mais jovens demonstraram maior grau de insatisfação se comparado com os servidores com maior idade. Consequentemente, a parcela mais jovem de servidores apresenta maior intensão de mudança de emprego.

Em relação aos motivos do ingresso na carreira de policial militar, os resultados verificaram que os mesmos estão relacionados em maior parte a questões de oportunidade e estabilidade financeira, e em menor parte por aptidão. A pesquisa também mostra que a maioria dos entrevistados sairia em busca de novas oportunidades de trabalho, caso surgissem.

Outro fator importante a ser observado é que $37,2 \%$ dos entrevistados acreditam que o tempo de formação profissional foi insuficiente para torná-los aptos para o serviço de policial militar.

Também identificou-se que, segundo a pesquisa, o salário não é compatível com a função exercida na segurança pública. A teoria de Herzberg considera o salário um importante fator higiênico quando não satisfatório. Dessa forma, faz-se necessário a inserção de elementos motivadores para elevar o nível de satisfação como oportunidades de melhorias, realização, progresso entre outros

Seria interessante, também, a introdução de novos conceitos administrativos no planejamento de recursos humanos, com vista em uma nova política de gerenciamento, baseada em novos princípios e ideias da administração moderna e, especialmente, em Programas de Qualidade de Vida no Trabalho (QVT) como forma de motivar os policiais militares.

Por fim, vê-se o quanto é necessário e importante fazer novas pesquisas sobre motivação e satisfação nas instituições públicas que permitam avaliar como está a relação entre os profissionais e a organização. Dessa maneira, a busca por políticas de gestão de pessoas que possibilitem valorizar o elemento humano para que tornem cada vez mais comprometidos em atingir os objetivos organizacionais.

\section{Referências}

AGAPITO, P. R.; SANTOS, C. B. D.; ALVES, C. H.; SÁ, C. R. C. B.; SANTOS, H. R. D. Análise da satisfação no trabalho e do cumprimento dos contratos psicológicos dos profissionais da Região do ABC Paulista. Revista Eletrônica Gestão e Serviços, v. 5, n. 1, p. 766-786, 2014.Disponível em: <https://www.metodista.br/revistas/revistas-ims/index.php/REGS/article/viewArticle/4465>. Acesso em: 14 dez. 2014.

ANDRADE, C. R.; PEREIRA, L. Z.; CKAGNAZAROFF, I. B. Elementos de satisfação e insatisfação no trabalho operacional: revisitando Herzberg. Revista Gestão \& Tecnologia, v.7, n.

163 Id en lime Revista de Psicologia. Ano 9, №. 26, Supl. Esp. Abril2015 - ISSN 1981-1179. Edição eletrônica em http://idonline.emnuvens.com.br/id 
1, p. 67-89, 2007 Disponível em: <http://www.spell.org.br/documentos /ver/24512/elementos-de-satisfacao-e-insatisfacao-no-trabalho-operacional-revisitando-herzberg/i/ptb>. Acesso em: 14 dez.2014.

BERGAMINI, C. W. Objetivos Motivacionais e Estilos de Comportamento. Revista de Administração, v. 13, n. 1, p. 11-32, São Paulo, 1978.

BRANDÃO, I. F. et al. Satisfação no serviço público: um estudo na Superintendência Regional do Trabalho e Emprego no Ceará. Read. Revista Eletrônica de Administração, Porto Alegre, v. 20, n. 1, p.90-113, abr. 2014. Disponível em: <http://www.spell.org.br/documentos/ver/28888/satisfacao-noservico-publico--um-estudo-na-superintendencia-regional-do-trabalho-e-emprego-no-ceara/i/pt-br > . Acesso em: 14 dez. 2015.

Diário de Pernambuco. Disponível em <http://blogs.diariodepernambuco.com.br /segurancapublica/?p=6771 > Acesso em 15 jan.

2015.

JUNIOR, A. S., MALINI, E., SILVA, P. O. M., FUNCHAL, B., SILVA, A. N. Qualidade De Vida No Trabalho E Níveis Hierárquicos. Revista Pretexto, v. 13 (1), p. 154-178, jan-mar 2012.

ROBBINS, S. P. Comportamento Organizacional. 11 ed. São Paulo: Pearson Prentice Hall, 2005.

\section{Como citar este artigo (Formato ABNT):}

CASSUNDÉ, F.R.S.A.; MORAES, A.C.B.; VASCONCELOS, A.B.; ALVES JÚNIOR, C.; SOUZA, E.C.; PEREIRA, R.D.; ALENCAR, R.R. Motivação e Satisfação no Trabalho da Polícia Militar: Um estudo de caso no Sertão pernambucano. Id on Line Revista de Psicologia, Abril de 2015, vol.9, n.26, Supl. Esp. p. 152-164. ISSN 1981-1189.

Recebido: 25/01/2015

Aceito:12/02/2015 